\title{
Comparison of Breast Conserving Surgery Followed by Radiation Therapy with Mastectomy Alone for Pathologic N1 Breast Cancer Patients in the Era of Anthracycline Plus Taxane-Based Chemotherapy: A Multicenter Retrospective Study (KROG 1418)
}

\author{
Gyu Sang Yoo, MD \\ Won Park, MD, PhD' \\ Jeong $\| \mathrm{Yu}, \mathrm{MD}, \mathrm{PhD}$ \\ Doo Ho Choi, MD, PhD ${ }^{1}$ \\ Yeon-Joo Kim, MD2 \\ Kyung Hwan Shin, MD, PhD 3 \\ Chan Woo Wee, MD \\ Kyubo Kim, MD, PhD ${ }^{4}$ \\ Kyung Ran Park, MD, PhD \\ Yong Bae Kim, MD, $\mathrm{PhD}{ }^{6}$ \\ Sung Ja Ahn, MD, $P h D^{7}$ \\ Jong Hoon Lee, MD, $P h D^{8}$ \\ Jin Hee Kim, MD, PhD ${ }^{9}$ \\ Mison Chun, MD, PhD ${ }^{10}$ \\ Hyung-Sik Lee, MD, PhD'11 \\ Jung Soo Kim, MD, PhD'2 \\ Jihye Cha, MD, $P h D^{13}$
}

*A list author's affiliations appears at the end of the paper.

Correspondence: Won Park, MD, PhD

Department of Radiation Oncology,

Samsung Medical Center, Sungkyunkwan

University School of Medicine, 81 Irwon-ro,

Gangnam-gu, Seoul 06351, Korea

Tel: 82-2-3410-2438

Fax: 82-2-3410-2619

E-mail: wonro.park@samsung.com

Co-correspondence: Kyung Hwan Shin, MD, PhD Department of Radiation Oncology,

Seoul National University College of Medicine, 101 Daehak-ro, Jongno-gu, Seoul 03080, Korea

Tel: 82-2-2072-2524

Fax: 82-2-765-3317

E-mail: radiat@snu.ac.kr

Received July 26, 2018

Accepted October 22, 2018

Published Online November 1, 2018

\section{Purpose}

We compared the oncologic outcomes of breast-conserving surgery plus radiation therapy (BCS+RT) and modified radical mastectomy (MRM) under anthracycline plus taxane-based (AT) regimens and investigated the role of adjuvant radiation therapy (RT) in patients with pathologic N1 (pN1) breast cancer treated by mastectomy.

\section{Materials and Methods}

We retrospectively reviewed the medical records of 2,011 patients with $\mathrm{pN} 1$ breast cancer who underwent BCS+RT or MRM alone at 12 institutions between January 2006 and December 2010. Two-to-one propensity score matching was performed for balances in variables between the groups.

\section{Results}

The median follow-up duration for the total cohort was 69 months (range, 1 to 114 months). After propensity score matching, 1,074 patients (676 in the BCS+RT group and 398 in the MRM-alone group) were analyzed finally. The overall survival, disease-free survival, locoregional failure-free survival, and regional failure-free survival (RFFS) curves of the BCS+RT group vs. MRM-alone group were not significantly different. The subgroup analysis revealed that in the group with both lymphovascular invasion (LVI) and histologic grade (HG) III, the BCS+RT showed significantly superior RFFS $(p=0.008)$. Lymphedema $(p=0.007)$ and radiation pneumonitis $(p=0.031)$ occurred more frequently in the BCS+RT group than in the MRM-alone group, significantly.

\section{Conclusion}

There are no differences in oncologic outcomes between BCS+RT and MRM-alone groups under the AT chemotherapy regimens for pN1 breast cancer. However, BCS+RT group showed superior RFFS to MRM-alone group in the patients with LVI and HG III. Adjuvant RT might be considerable for pN1 breast cancer patients with LVI and HG III.

\section{Key words}

Breast neoplasms, Pathologic N1, Breast conserving surgery, Radiotherapy, Mastectomy, Anthracyclines, Taxane, Survival 


\section{Introduction}

Randomized trials comparing breast-conservation surgery (BCS) plus adjuvant radiation therapy (RT) with mastectomy alone in early-stage breast cancer have shown no differences in oncologic outcomes [1-6]. On the other hand, several recent population-based studies reported that BCS plus RT $(\mathrm{BCS}+\mathrm{RT})$ resulted in better oncologic outcomes than mastectomy according to $\mathrm{T}$ or $\mathrm{N}$ category [7-11]. The role of adjuvant RT after mastectomy for pN1 breast cancer is also a controversial issue. Key randomized trials showed better oncologic outcomes in the post-mastectomy RT (PMRT) group compared with the non-PMRT group for breast cancer with nodal metastasis $[12,13]$. Subgroup analysis by the Danish Breast Cancer Cooperative Group (DBCG) 82 B\&C randomized trial [13] and meta-analysis from the Early Breast Cancer Trialists' Collaborative Group (EBCTCG) [14] reported that PMRT had the benefit of local control for subgroups with 1-3 axillary nodal metastases. The National Comprehensive Cancer Network (NCCN) clinical practice guideline recommends strong consideration of PMRT for N1 breast cancer [15]. However, the chemotherapeutic regimens of these studies are not the modern one, but mostly the CMF (cyclophosphamide, methotrexate, and 5-fluorouracil) regimen, which is less effective [16,17].

Anthracycline plus taxane-based (AT) chemotherapy is the currently recommended adjuvant treatment in the breast cancer, especially with nodal metastasis [15]. This regimen showed benefits in local control as well as overall survival (OS) comparing with previous chemotherapy regimens $[18,19]$. In the era of the AT regimen, the role of PMRT for $\mathrm{pN} 1$ disease is still unclear $[20,21]$. Therefore, we performed this study to compare oncologic outcomes between BCS+RT and modified radical mastectomy (MRM) alone under the AT regimen and to investigate the role of adjuvant $\mathrm{RT}$ in patients with $\mathrm{pN} 1$ breast cancer treated by mastectomy.

\section{Materials and Methods}

\section{Patients}

We retrospectively reviewed the medical records of 2,011 patients with pathologic N1 breast cancer who underwent BCS+RT or MRM alone at 12 institutions in South Korea between Jan 2006 and Dec 2010.

Information was obtained from medical records regarding pathologic tumor features, including molecular subtype, tumor size, resection margin, lymphovascular invasion (LVI), nuclear grade (NG), histologic grade (HG), number of lymph nodes (LN) with metastasis, and extracapsular extension (ECE). Patients were excluded because of non-AT chemotherapy $(\mathrm{n}=47)$, BCS without adjuvant RT $(\mathrm{n}=37)$ and PMRT $(\mathrm{n}=157)$, and insufficient medical records $(\mathrm{n}=296)$. Finally, 1,474 patients were included in the analysis.

\section{Treatment}

BCS+RT was performed for 1,047 patients $(71.0 \%)$. The median dose of adjuvant RT on the whole breast was 50 Gy (range, 45 to $50.4 \mathrm{~Gy}$ ). Tumor bed boost with median dose of $10 \mathrm{~Gy}$ (range, 5 to $16 \mathrm{~Gy}$ ) was applied to 1,026 patients. RT to the supraclavicular fossa with a median dose of $50 \mathrm{~Gy}$ (range, 45 to $50.4 \mathrm{~Gy}$ ) was performed in 320 patients (30.6\%), and $37(3.5 \%)$ of them received RT to the internal mammary area with a median dose of $50.4 \mathrm{~Gy}$ (range, 45 to $50.4 \mathrm{~Gy}$ ). RT plans followed the general principles of RT to the whole breast. Median number of axillary LN dissections performed was 16 (range, 1 to 47). Most patients (99.8\%) were treated with an AC (adriamycin and cyclophosphamide) plus T (taxane) regimen, while others were administrated the FAC (fluorouracil, adriamycin, and cytoxan) plus $\mathrm{T}$ regimen $(0.1 \%)$ or EC (epirubicin and cyclophosphamide) plus $\mathrm{T}$ regimen $(0.1 \%)$.

MRM alone was performed for 427 patients (29.0\%). All patients in the MRM-alone group received a median of 19 axillary LN dissections (range, 2 to 43). AC plus T was administered to most patients (99.8\%) in the MRM group. Other patients received the FEC (fluorouracil, epirubicin, and cytoxan) plus $\mathrm{T}$ regimen $(0.2 \%)$. None of this group underwent adjuvant $\mathrm{RT}$.

\section{Statistical analysis}

OS, disease-free survival (DFS), locoregional failure-free survival (LRFFS), and regional failure-free survival (RFFS) were defined as the interval from surgery to death, cancer recurrence, locoregional recurrence, and regional recurrence, respectively. The chi-square test or Fisher exact test was used to compare patient characteristics and patterns of failure between the BCS+RT and MRM-alone group. The Kaplan-Meier method was used to estimate survival curves. Log-rank tests were performed to compare survival between groups for various variables. Cox regression analysis was chosen for multivariate analysis to determine the independent prognostic factors for outcomes. A two-sided p-value of $<0.05$ was considered statistically significant. Statistical analyses were performed with SPSS ver. 22.0 (IBM Corp., Armonk, NY). Analyses were also performed for subgroups defined according to the number of risk factors identified as significant in multivariate analyses for DFS. 
Table 1. Baseline characteristics of study patients

\begin{tabular}{|c|c|c|c|c|c|c|}
\hline \multirow[b]{2}{*}{ Characteristic } & \multicolumn{3}{|c|}{ Before matching } & \multicolumn{3}{|c|}{ After matching } \\
\hline & $\begin{array}{l}\text { BCS+RT } \\
(n=1,047)\end{array}$ & $\begin{array}{l}\text { MRM alone } \\
\quad(n=427)\end{array}$ & p-value & $\begin{array}{c}\text { BCS+RT } \\
(n=676)\end{array}$ & $\begin{array}{l}\text { MRM alone } \\
\qquad(n=398)\end{array}$ & p-value \\
\hline Age (yr) & $47.4 \pm 8.6$ & $48.9 \pm 9.4$ & 0.004 & $48.1 \pm 8.9$ & $48.7 \pm 9.3$ & 0.319 \\
\hline \multicolumn{7}{|l|}{ Menopausal status } \\
\hline Premenopause & $676(64.6)$ & $251(58.8)$ & 0.043 & $415(61.4)$ & $238(59.8)$ & 0.604 \\
\hline Postmenopause & $371(35.4)$ & $176(41.2)$ & & $261(38.6)$ & $160(40.2)$ & \\
\hline \multicolumn{7}{|l|}{ Site } \\
\hline Left & $504(48.1)$ & $217(50.8)$ & 0.380 & $330(48.8)$ & $199(50.0)$ & 0.732 \\
\hline Right & $543(51.9)$ & $210(49.2)$ & & $346(51.2)$ & $199(50.0)$ & \\
\hline \multicolumn{7}{|l|}{ Pathology } \\
\hline IDC & $984(94.0)$ & $413(96.7)$ & 0.044 & $648(95.9)$ & $384(96.5)$ & 0.601 \\
\hline Non-IDC & $63(6.0)$ & $14(3.3)$ & & $28(4.1)$ & $14(3.5)$ & \\
\hline \multicolumn{7}{|c|}{ Pathologic T category } \\
\hline 1 & $507(48.4)$ & $160(37.5)$ & 0.000 & $280(41.4)$ & $160(40.2)$ & 0.897 \\
\hline 2 & $532(50.8)$ & $265(62.1)$ & & $393(58.1)$ & $236(59.3)$ & \\
\hline 3 & $8(0.8)$ & $2(0.5)$ & & $3(0.4)$ & $2(0.5)$ & \\
\hline \multicolumn{7}{|c|}{ No. of LN metastases } \\
\hline 1 & $603(57.6)$ & $231(54.1)$ & 0.070 & $381(56.4)$ & $218(54.8)$ & 0.722 \\
\hline $2-3$ & $444(42.4)$ & $196(45.9)$ & & $295(43.6)$ & $180(45.2)$ & \\
\hline \multicolumn{7}{|l|}{ LN management } \\
\hline SLNB only & $78(7.4)$ & $24(5.6)$ & 0.258 & $46(6.8)$ & $22(5.5)$ & 0.438 \\
\hline ALND & $969(92.6)$ & $403(94.4)$ & & $630(93.2)$ & $376(94.5)$ & \\
\hline \multicolumn{7}{|l|}{ Positive LN ratio } \\
\hline$\leq 0.1$ & $506(48.3)$ & $233(54.6)$ & 0.034 & $338(50.0)$ & $219(55.0)$ & 0.101 \\
\hline$>0.1$ & $541(51.7)$ & $194(45.4)$ & & $338(50.0)$ & $179(45.0)$ & \\
\hline \multicolumn{7}{|l|}{ LVI } \\
\hline No & $370(35.3)$ & $273(63.9)$ & 0.000 & $397(58.7)$ & $244(61.3)$ & 0.068 \\
\hline Yes & $677(64.7)$ & $154(36.1)$ & & $279(41.3)$ & $154(38.7)$ & \\
\hline \multicolumn{7}{|l|}{ Nuclear grade } \\
\hline $1-2$ & $599(57.2)$ & $200(46.8)$ & 0.000 & $324(47.9)$ & $200(50.3)$ & 0.412 \\
\hline 3 & $448(42.8)$ & $227(53.2)$ & & $352(52.1)$ & $198(49.7)$ & \\
\hline \multicolumn{7}{|l|}{ Histologic grade } \\
\hline I-II & $642(61.3)$ & $216(50.6)$ & 0.000 & $301(44.5)$ & $185(46.5)$ & 0.482 \\
\hline III & 405 (38.7) & $211(49.4)$ & & $375(55.5)$ & $213(53.5)$ & \\
\hline \multicolumn{7}{|l|}{ Molecular subtype } \\
\hline Luminal A & $459(43.8)$ & $192(45.0)$ & 0.736 & $375(55.4)$ & $216(54.3)$ & 0.736 \\
\hline Non-luminal A & $588(56.2)$ & $235(55.0)$ & & $301(44.6)$ & $182(45.7)$ & \\
\hline \multicolumn{7}{|l|}{ ECE } \\
\hline No & $578(55.2)$ & $267(62.5)$ & 0.012 & $382(56.5)$ & $239(60.1)$ & 0.247 \\
\hline Yes & $469(44.8)$ & $160(37.5)$ & & $294(43.5)$ & $159(39.9)$ & \\
\hline
\end{tabular}

Values are presented as mean \pm standard deviation or number $(\%)$. BCS, breast conserving surgery; RT, radiation therapy; MRM, modified radical mastectomy; IDC, invasive ductal carcinoma; LN, lymph node; SLNB, sentinel lymph node biopsy; ALND, axillary lymph node dissection; LVI, lymphovascular invasion; ECE, extracapsular extension.

Two-to-one propensity score matching was performed to eliminate imbalances in variables between the two treatment groups. Matching variables were age, menopause status, site, pathology, pathologic T staging, number of LNs with metas- tasis, LVI, NG, HG, molecular subtype, and ECE. R Statistical Software ver. 3.2.3 (The R foundation for Statistical Analyses, Vienna, Austria) was utilized in propensity score matching. 
Table 2. Patterns of the first failure according to field of radiotherapy

\begin{tabular}{lccc} 
Sites of the first failure & $\begin{array}{c}\text { BCS+RT } \\
(\mathbf{n = 6 7 6 )}\end{array}$ & $\begin{array}{c}\text { MRM alone } \\
(\mathbf{n = 3 9 8 )}\end{array}$ & $\begin{array}{c}\text { p-value } \\
\text { Isolated loco-regional only }\end{array}$ \\
$\quad 10(1.5)$ & $5(1.5)$ & 0.971 \\
$\quad$ Local only & $5(0.7)$ & $2(0.5)$ & 1.000 \\
$\quad$ Regional only & $5(0.7)$ & $4(1.0)$ & 0.733 \\
Distant only & $28(4.1)$ & $23(5.8)$ & 0.223 \\
Simultaneous loco-regional and distant & $12(1.8)$ & $13(3.3)$ & 0.118 \\
Total & $50(7.4)$ & $42(10.6)$ & 0.074 \\
\hline
\end{tabular}

Values are presented as number (\%). BCS, breast conserving surgery; RT, radiation therapy; MRM, modified radical mastectomy.

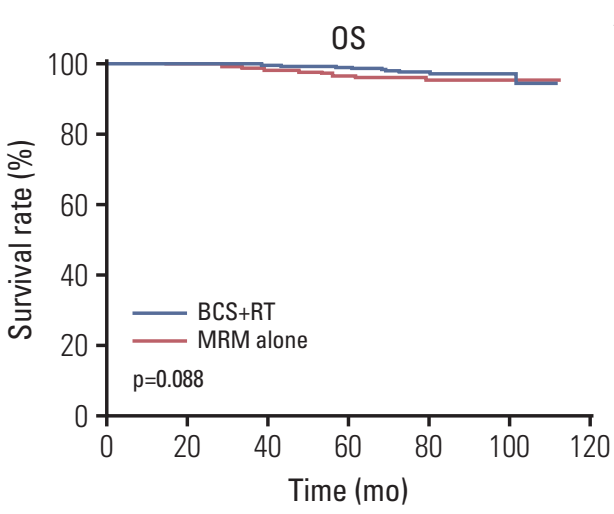

No. at risk

$\begin{array}{llllllll}\text { BCS+RT } & 676 & 667 & 654 & 458 & 192 & 51 & 1\end{array}$

$\begin{array}{llllllll}\text { MRM alone } & 398 & 394 & 384 & 291 & 132 & 41 & 1\end{array}$

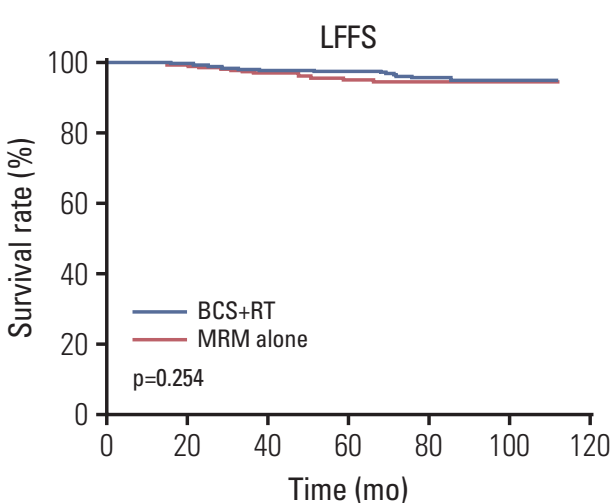

No. at risk

$\begin{array}{llllllll}\text { BCS+RT } & 676 & 665 & 643 & 449 & 190 & 50 & 1\end{array}$

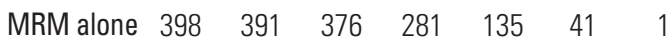

A

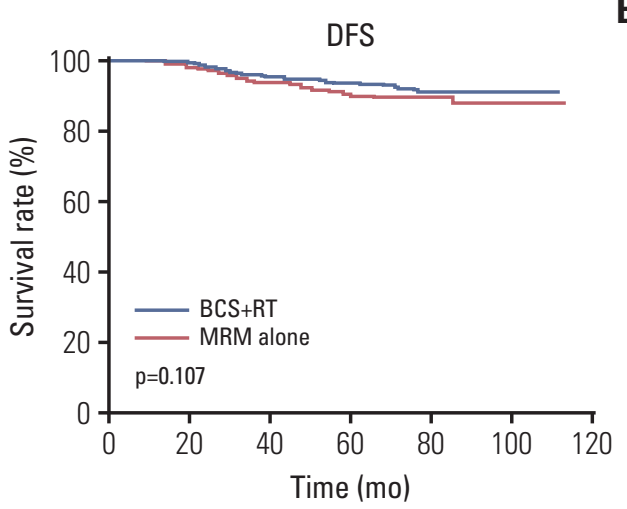

No. at risk

$\begin{array}{llllllll}\text { BCS+RT } & 676 & 663 & 626 & 430 & 182 & 48 & 1\end{array}$

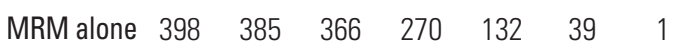

C

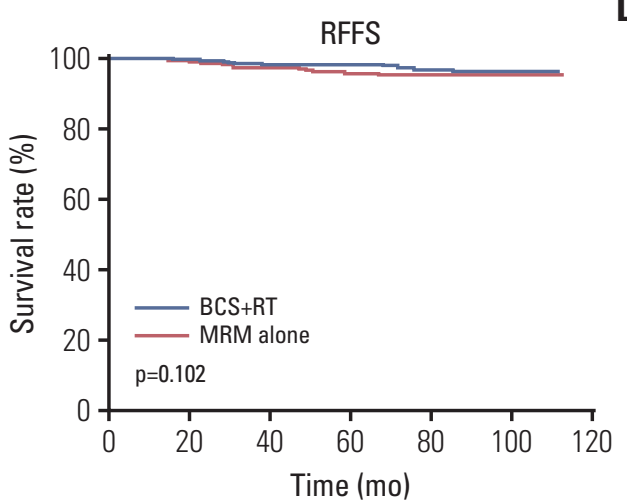

No. at risk

$\begin{array}{llllllll}\text { BCS+RT } & 676 & 666 & 647 & 451 & 189 & 50 & 1\end{array}$

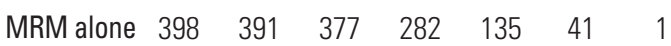

Fig. 1. Survival curves according to treatment group. Overall survival (OS) (A), disease-free survival (DFS) (B), locoregional failure-free survival (LFFS) (C), and regional failure-free survival (RFFS) (D). BCS+RT, breast conserving surgery plus radiation therapy; MRM, modified radical mastectomy. 
Table 3. Univariate and multivariate analysis (OS)

\begin{tabular}{|c|c|c|c|c|}
\hline \multirow{2}{*}{ Characteristic } & \multicolumn{2}{|c|}{ Univariate analysis } & \multicolumn{2}{|c|}{ Multivariate analysis } \\
\hline & 5-Year OS rate $(\%)$ & p-value & HR $(95 \%$ CI) & p-value \\
\hline \multicolumn{5}{|l|}{ Age (yr) } \\
\hline$\leq 55$ & 97.7 & 0.828 & - & - \\
\hline$>55$ & 97.5 & & - & \\
\hline \multicolumn{5}{|l|}{ Menopause status } \\
\hline Premenopause & 98.6 & 0.072 & $0.592(0.295-1.190)$ & 0.141 \\
\hline Postmenopause & 96.0 & & - & \\
\hline \multicolumn{5}{|l|}{ Site } \\
\hline Left & 97.3 & 0.737 & - & - \\
\hline Right & 97.9 & & - & \\
\hline \multicolumn{5}{|l|}{ Pathology } \\
\hline IDC & 97.6 & 0.725 & - & - \\
\hline Non-IDC & 97.7 & & - & \\
\hline \multicolumn{5}{|c|}{ Pathologic $\mathrm{T}$ category } \\
\hline 1 & 97.9 & 0.731 & - & - \\
\hline $2-3$ & 97.4 & & - & \\
\hline \multicolumn{5}{|c|}{ No. of LN metastases } \\
\hline 1 & 97.8 & 0.443 & - & - \\
\hline 2 & 97.4 & & - & \\
\hline \multicolumn{5}{|l|}{ LVI } \\
\hline No & 98.0 & 0.342 & - & - \\
\hline Yes & 97.2 & & - & \\
\hline \multicolumn{5}{|l|}{ Nuclear grade } \\
\hline $1-2$ & 98.9 & 0.002 & $0.544(0.174-1.704)$ & 0.296 \\
\hline 3 & 96.2 & & - & \\
\hline \multicolumn{5}{|l|}{ Histologic grade } \\
\hline I-II & 99.0 & 0.004 & $0.773(0.269-2.220)$ & 0.632 \\
\hline III & 95.9 & & - & \\
\hline \multicolumn{5}{|l|}{ Molecular subtype } \\
\hline Luminal A & 99.1 & 0.001 & $0.327(0.129-0.825)$ & 0.018 \\
\hline Non-luminal A & 96.3 & & - & \\
\hline \multicolumn{5}{|l|}{ ECE } \\
\hline No & 97.6 & 0.771 & - & - \\
\hline Yes & 97.7 & & - & \\
\hline \multicolumn{5}{|l|}{ Modality } \\
\hline $\mathrm{BCS}+\mathrm{RT}$ & 98.6 & 0.088 & $0.597(0.297-1.200)$ & 0.147 \\
\hline MRM alone & 96.1 & & - & \\
\hline
\end{tabular}

OS, overall survival; HR, hazard ratio; CI, confidence interval; IDC, invasive ductal carcinoma; LN, lymph node; LVI, lymphovascular invasion; ECE, extracapsular extension; BCS, breast conserving surgery; RT, radiation therapy; MRM; modified radical mastectomy.

\section{Ethical statement}

This study was approved by the Institutional Review Board (IRB) of each hospital and performed in accordance with the principles of the Declaration of Helsinki. Each IRB approved a waiver of informed consent.

\section{Results}

\section{Patient characteristics}

The median follow-up duration for the total cohort was 69 months (range, 1 to 114 months). The 5-year rates of OS, DFS, LRFFS, and RFFS of the total cohort were $98.0 \%, 92.4 \%$, 
Table 4. Univariate and multivariate analysis (DFS)

\begin{tabular}{|c|c|c|c|c|}
\hline \multirow{2}{*}{ Characteristic } & \multicolumn{2}{|c|}{ Univariate analysis } & \multicolumn{2}{|c|}{ Multivariate analysis } \\
\hline & 5-Year DFS rate $(\%)$ & p-value & HR $(95 \%$ CI $)$ & p-value \\
\hline \multicolumn{5}{|l|}{ Age (yr) } \\
\hline$\leq 55$ & 91.9 & 0.987 & - & - \\
\hline$>55$ & 92.3 & & - & \\
\hline \multicolumn{5}{|l|}{ Menopause status } \\
\hline Premenopause & 92.5 & 0.248 & - & - \\
\hline Postmenopause & 91.0 & & - & \\
\hline \multicolumn{5}{|l|}{ Site } \\
\hline Left & 90.7 & 0.171 & $1.239(0.818-1.875)$ & 0.311 \\
\hline Right & 93.2 & & - & \\
\hline \multicolumn{5}{|l|}{ Pathology } \\
\hline IDC & 91.9 & 0.598 & - & - \\
\hline Non-IDC & 93.2 & & - & \\
\hline \multicolumn{5}{|c|}{ Pathologic T category } \\
\hline 1 & 95.0 & 0.001 & $0.665(0.415-1.064)$ & 0.089 \\
\hline $2-3$ & 89.6 & & - & \\
\hline \multicolumn{5}{|c|}{ No. of LN metastases } \\
\hline 1 & 93.2 & 0.126 & $0.823(0.545-1.244)$ & 0.356 \\
\hline $2-3$ & 90.4 & & - & \\
\hline \multicolumn{5}{|l|}{ LVI } \\
\hline No & 94.6 & $<0.001$ & $0.472(0.304-0.731)$ & 0.001 \\
\hline Yes & 88.7 & & - & \\
\hline \multicolumn{5}{|l|}{ Nuclear grade } \\
\hline $1-2$ & 95.4 & $<0.001$ & $0.715(0.389-1.314)$ & 0.280 \\
\hline 3 & 88.0 & & - & \\
\hline \multicolumn{5}{|l|}{ Histologic grade } \\
\hline I-II & 96.4 & $<0.001$ & $0.254(0.134-0.481)$ & 0.001 \\
\hline III & 86.1 & & - & \\
\hline \multicolumn{5}{|l|}{ Molecular subtype } \\
\hline Luminal A & 94.4 & 0.024 & $0.849(0.544-1.326)$ & 0.472 \\
\hline Non-luminal A & 90.0 & & - & \\
\hline \multicolumn{5}{|l|}{ ECE } \\
\hline No & 91.8 & 0.771 & - & - \\
\hline Yes & 92.0 & & - & \\
\hline \multicolumn{5}{|l|}{ Modality } \\
\hline $\mathrm{BCS}+\mathrm{RT}$ & 93.3 & 0.107 & $0.702(0.463-1.065)$ & 0.096 \\
\hline MRM alone & 89.7 & & - & \\
\hline
\end{tabular}

DFS, disease-free survival; HR, hazard ratio; CI, confidence interval; IDC, invasive ductal carcinoma; LN, lymph node; LVI, lymphovascular invasion; ECE, extracapsular extension; BCS, breast conserving surgery; RT, radiation therapy; MRM; modified radical mastectomy.

$97.0 \%$, and $97.6 \%$, respectively. Among the total cohort, there were significant differences in age, menopausal status, pathology, pathologic T category, LVI, NG, HG, and ECE between the BCS+RT and MRM-alone groups. After propensity score matching, a total of 1,074 patients (676 in the BCS+ RT group and 398 in the MRM-alone group) were included for analysis. The patient characteristics are summarized in
Table 1. The number of dissected LNs were 16 (range, 1 to 42) in BCS+RT group and 18 (range, 2 to 42) in MRM-alone group. 
Table 5. Univariate and multivariate analysis (RFFS)

\begin{tabular}{|c|c|c|c|c|}
\hline \multirow{2}{*}{ Characteristic } & \multicolumn{2}{|c|}{ Univariate analysis } & \multicolumn{2}{|c|}{ Multivariate analysis } \\
\hline & 5-Year RFFS rate $(\%)$ & p-value & HR $(95 \% \mathrm{CI})$ & p-value \\
\hline \multicolumn{5}{|l|}{ Age (yr) } \\
\hline$\leq 55$ & 97.2 & 0.915 & - & - \\
\hline$>55$ & 98.0 & & - & \\
\hline \multicolumn{5}{|l|}{ Menopause status } \\
\hline Premenopause & 97.3 & 0.571 & - & - \\
\hline Postmenopause & 97.4 & & - & \\
\hline \multicolumn{5}{|l|}{ Site } \\
\hline Left & 96.9 & 0.571 & - & - \\
\hline Right & 97.8 & & - & \\
\hline \multicolumn{5}{|l|}{ Pathology } \\
\hline IDC & 97.2 & 0.218 & - & - \\
\hline Non-IDC & 100 & & - & \\
\hline \multicolumn{5}{|c|}{ Pathologic T category } \\
\hline 1 & 98.2 & 0.120 & $0.890(0.417-1.900)$ & 0.764 \\
\hline $2-3$ & 96.7 & & - & \\
\hline \multicolumn{5}{|c|}{ No. of LN metastases } \\
\hline 1 & 97.1 & 0.638 & - & - \\
\hline $2-3$ & 97.7 & & - & \\
\hline \multicolumn{5}{|l|}{ LVI } \\
\hline No & 98.6 & 0.004 & $0.340(0.159-0.726)$ & 0.005 \\
\hline Yes & 95.9 & & - & \\
\hline \multicolumn{5}{|l|}{ Nuclear grade } \\
\hline $1-2$ & 98.8 & 0.021 & $0.527(0.205-1.356)$ & 0.184 \\
\hline 3 & 95.7 & & - & \\
\hline \multicolumn{5}{|l|}{ Histologic grade } \\
\hline I-II & 99.4 & $<0.001$ & $0.138(0.047-0.408)$ & $<0.001$ \\
\hline III & 94.6 & & - & \\
\hline \multicolumn{5}{|l|}{ Molecular subtype } \\
\hline Luminal A & 98.5 & 0.193 & $0.902(0.431-1.887)$ & 0.785 \\
\hline Non-luminal A & 96.4 & & - & \\
\hline \multicolumn{5}{|l|}{ ECE } \\
\hline No & 97.3 & 0.503 & - & - \\
\hline Yes & 97.3 & & - & \\
\hline \multicolumn{5}{|l|}{ Modality } \\
\hline $\mathrm{BCS}+\mathrm{RT}$ & 98.3 & 0.102 & $0.523(0.262-1.044)$ & 0.066 \\
\hline MRM & 95.7 & & - & \\
\hline
\end{tabular}

RFFS, regional failure-free survival; HR, hazard ratio; CI, confidence interval; IDC, invasive ductal carcinoma; LN, lymph node; LVI, lymphovascular invasion; ECE, extracapsular extension; BCS, breast conserving; RT, radiation therapy; MRM; modified radical mastectomy.

\section{Treatment outcome}

Among 1,074 patients, $92(8.6 \%)$ experienced disease recurence. The patterns of first failure were not significantly different between the groups (Table 2). The OS, DFS, LRFFS, and RFFS rates of the BCS+RT group vs. MRM-alone group at 5 years were $98.6 \%$ vs. $96.1 \%$ ( $p=0.088), 93.3 \%$ vs. $89.7 \%$ $(p=0.107), 97.6 \%$ vs. $95.2 \%(p=0.254)$, and $98.3 \%$ vs. $95.7 \%$ $(\mathrm{p}=0.102)$, respectively (Fig. 1). On multivariate analysis, luminal A type was identified as an independent prognostic factor associated with better OS (Table 3). The multivariate analyses revealed that LVI and HG were independent prognosticators associated with DFS and RFFS (Tables 4 and 5).

Three subgroups were determined according to the num- 


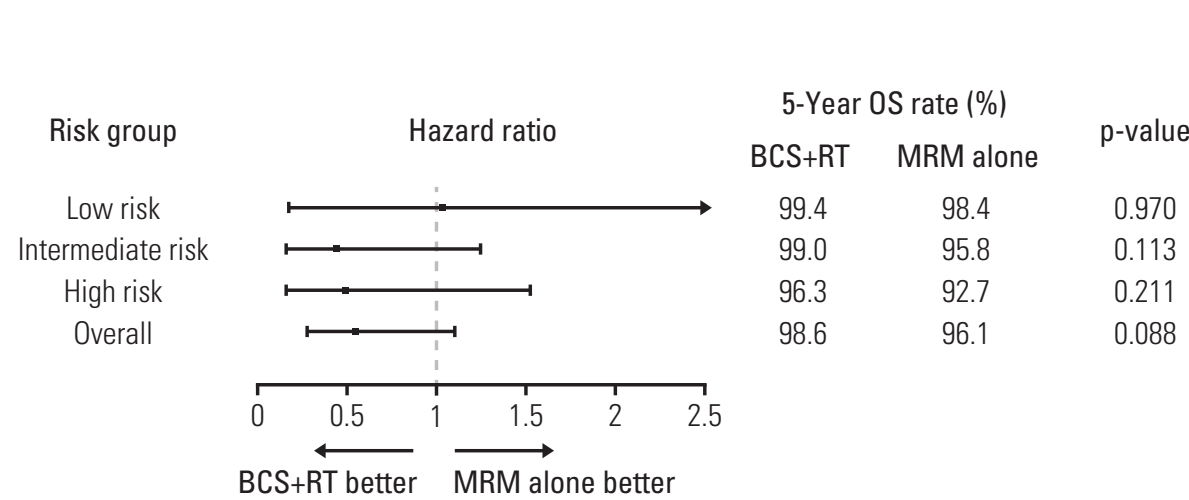

\section{B}

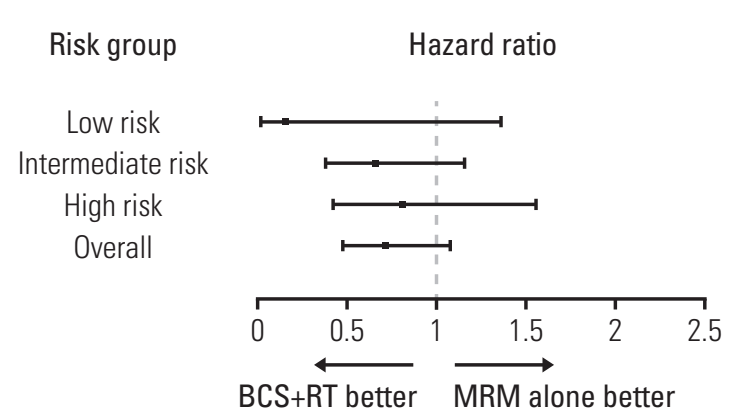

\begin{tabular}{ccc}
\multicolumn{2}{c}{ 5-Year DFS rate (\%) } & \\
BCS+RT & MRM alone & -value \\
99.5 & 96.8 & 0.052 \\
93.6 & 88.6 & 0.142 \\
83.7 & 79.6 & 0.522 \\
93.3 & 89.7 & 0.107
\end{tabular}

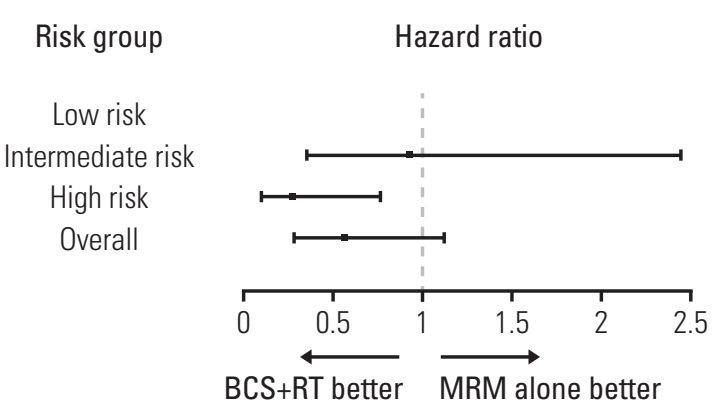

\begin{tabular}{ccc}
\multicolumn{2}{c}{ 5-Year RFFS rate (\%) } & \\
BCS+RT & MRM alone & p-value \\
100 & 100 & NA $^{\text {a) }}$ \\
98.4 & 96.6 & 0.890 \\
95.8 & 85.4 & 0.008 \\
98.3 & 95.7 & 0.102
\end{tabular}

Fig. 2. Subgroup analyses according to risk group for overall survival (OS) (A), disease-free survival (DFS) (B), and regional failure-free survival (RFFS) (C). BCS+RT, breast conserving surgery plus radiation therapy; MRM, modified radical mastectomy; NA, not applicable, a)Hazard ratio was not calculated for RFFS in the low risk group because there was no regional failure in that subgroup.

Table 6. Treatment-related toxicities

\begin{tabular}{|c|c|c|c|c|c|c|c|}
\hline \multirow{2}{*}{ Morbidity } & \multicolumn{3}{|c|}{$\mathrm{BCS}+\mathrm{RT}(\mathrm{n}=676)$} & \multicolumn{3}{|c|}{ MRM alone (n=398) } & \multirow{2}{*}{ p-valuc } \\
\hline & Grade 1 & Grade $\geq 2$ & Total & Grade 1 & Grade $\geq 2$ & Total & \\
\hline Lymphedema & $69(10.2)$ & $22(3.3)$ & 91 (13.5) & $26(6.5)$ & $6(1.5)$ & $32(8.0)$ & 0.007 \\
\hline Pneumonitis & $8(1.2)$ & $1(0.1)$ & $9(1.3)$ & 0 & 0 & 0 & 0.031 \\
\hline
\end{tabular}

Values are presented as number (\%). BCS, breast conserving surgery; RT, radiation therapy; MRM, modified radical mastectomy. 
ber of risk factors (positive LVI and HG of III) identified in multivariate analysis for DFS and RFFS: the low risk group $(\mathrm{n}=346)$ had no risk factors, the intermediate risk group $(\mathrm{n}=512)$ had one risk factor, and the high risk group $(\mathrm{n}=216)$ had two risk factors. For the high risk group, BCS+RT showed significantly superior RFFS (99.5\% vs. $96.8 \%, \mathrm{p}=0.008$ ) (Fig. 2). Although there was also a tendency for BCS+RT to have better DFS for all risk groups, there were no statistically significant differences (Fig. 2).

\section{Toxicity}

Lymphedema and radiation pneumonitis occurred more frequently in the BCS+RT group than in the MRM-alone group (Table 6). A total of $8.0 \%$ of patients in the MRM-alone group showed lymphedema, while $13.5 \%$ of patients presented with lymphedema after $\mathrm{BCS}+\mathrm{RT}(\mathrm{p}=0.007)$. Radiation pneumonitis was present in 1.3\% of patients in the BCS+RT group, whereas no patient in the MRM group showed radiation pneumonitis $(\mathrm{p}=0.031)$.

\section{Discussion}

Randomized trials comparing BCS+RT with mastectomy in early-stage breast cancer have shown comparable oncologic outcomes by long-term follow-up data [1-6]. However, several recent population-based studies reported that BCS+RT resulted in superior oncologic outcomes compared to mastectomy [7-11]. There are several reasons for this inconsistency in results between historic randomized trials and population-based studies. Those randomized trials were conducted in the 1980s with outdated diagnostic and therapeutic procedures; therefore, local recurrence was much higher $[11,22]$. Differences in study designs and patient populations may be additional reasons for inconsistent results between randomized trials and population-based studies [23]. The evolution of chemotherapy for early breast cancer may also deviate from the results of historic randomized trials $[18,19]$. Therefore, special caution is required in interpreting those randomized trials in current practice. Those population-based studies also have some limitations. The chemotherapy regimens were not standard. In addition, comparisons between treatment modalities were stratified only according to pathologic $\mathrm{T}$ or $\mathrm{N}$ category, not according to any other histologic or molecular subtype-based characteristics. To our knowledge, the current research is the first study to compare treatment outcomes between BCS+RT and MRM alone under a modern and homogeneous chemotherapy regimen. In addition, the treatment outcomes were compared according to subgroups stratified with various pathological variables for $\mathrm{pN} 1$ breast cancer. The inhomogeneity of the demographic and histologic properties was amended by propensity score matching.

The oncologic outcomes were not significantly different between treatment modalities. Among population-based studies, two reported the outcome of the $\mathrm{pN} 1$ subgroup. Chen et al. [8] used the National Cancer Database and reported the adjusted hazard ratio of mastectomy alone as 1.44 (range, 2.31 to $1.53 ; p<0.001$ ) over BCS+RT in patients with $\mathrm{pN} 1$ breast cancer. van Maaren et al. [11] analyzed patients selected from the Netherlands Cancer Registry and reported a higher mortality risk rate in the mastectomy compared with the BCS+RT. However, in those studies, mastectomy groups contained higher proportions of patients with large and multi-centric tumors, which are known prognostic factors associated with inferior LRFFS and OS. In addition, information regarding detailed chemotherapy regimen was not clarified, and a considerable proportion of patients treated with chemotherapy were included in the study population. In the modern chemotherapy era, the outcome of mastectomy alone has improved $[18,19]$. In particular, some studies have specifically reported that patients with $1-3$ positive LNs showed improvement in oncologic outcomes $[20,24,25]$. Therefore, the results are inconsistent, with the current study showing better outcomes for the mastectomy group than those studies.

The role of PMRT is also a controversial issue for $\mathrm{pN} 1$ nonmetastatic breast cancer. The DBCG $82 \mathrm{~B} \& \mathrm{C}$ trial and EBCTCG revealed that PMRT reduced mortality rates regardless of the number of LN metastases $[6,13,14]$. On the other hand, recent retrospective studies showed that addition of PMRT in patients with pN1 breast cancer seems to have no significant impact on oncologic outcomes in the modern chemotherapy era $[20,24,25]$. In the current study, the benefit of PMRT was not evaluated because patients who received PMRT were excluded from analyses. However, in the highrisk subgroup with LVI and HG 3, which were identified as independent factors associated with poor DFS, the BCS+RT group showed significantly better RFFS than the MRM-alone group. This implied that there might be a role of adjuvant RT in reducing regional recurrence for patients with LVI and HG 3 , which are well-known risk factors related to poor locoregional control and LN metastasis [20,26-28]. Therefore, PMRT is a consideration for patients with LVI and HG III even in the modern chemotherapy era. Further large scale randomized trials with stratification according to detailed risk groups are necessary to identify the role of PMRT in $\mathrm{pN} 1$ non-metastatic breast cancer.

There are several limitations in the current study. First, there is inevitable selection bias due to its retrospective nature. Although the propensity score matching method was 
utilized to balance treatment groups, some variables that were excluded from score matching might have been unevenly distributed. The pathologic data were collected from several different institutions, so bias regarding pathologic information also could not be excluded. Finally, the relatively short follow-up duration of the current study is also a limitation. The median follow-up duration of the total cohort was 69 months, which is not enough to detect late recurrence and treatment-related sequelae [29]. Therefore, further follow-up is required to compare long-term oncologic outcomes and adverse effects between treatment groups.

In conclusion, there are no differences in OS, DFS, LRFFS, and RFFS between BCS+RT and MRM alone under the AT chemotherapy regimen for patients with $\mathrm{pN} 1$ non-breast cancer. However, BCS+RT showed superior RFFS in patients with LVI and HG III, implying that adjuvant RT potentially has a role in reducing regional recurrence. Therefore, PMRT might be considerable for patients with LVI and HG 3.

\section{Conflicts of Interest}

Conflict of interest relevant to this article was not reported.

\section{Acknowledgments}

This study was supported by a grant from the National R\&D Program for Cancer Control, Ministry of Health \& Welfare, Republic of Korea (1720170).

\section{Author Details}

${ }^{1}$ Department of Radiation Oncology, Samsung Medical Center, Sungkyunkwan University School of Medicine, Seoul, ${ }^{2}$ Center for Breast Cancer, Research Institute and Hospital, National Cancer Center, Goyang, ${ }^{3}$ Department of Radiation Oncology, Seoul National University College of Medicine, Seoul, ${ }^{4}$ Department of Radiation Oncology, Ewha Womans University Mokdong Hospital, Ewha Womans University School of Medicine, Seoul, ${ }^{5}$ Department of Radiation Oncology, Kosin University Gospel Hospital, Busan, ${ }^{6}$ Department of Radiation Oncology, Yonsei Cancer Center, Yonsei University College of Medicine, Seoul, '7Department of Radiation Oncology, Chonnam National University Medical School, Gwangju, ${ }^{8}$ Department of Radiation Oncology, St. Vincent's Hospital, College of Medicine, The Catholic University of Korea, Suwon, ${ }^{9}$ Department of Radiation Oncology, Keimyung University Dongsan Medical Center, Keimyung University School of Medicine, Daegu, ${ }^{10}$ Department of Radiation Oncology, Ajou University School of Medicine, Suwon, ${ }^{11}$ Department of Radiation Oncology, Dong-A University Hospital, Dong-A University School of Medicine, Busan, ${ }^{12}$ Department of Radiation Oncology, Chonbuk National University Medical School, Jeonju, ${ }^{13}$ Department of Radiation Oncology, Wonju Severance Christian Hospital, Wonju, Korea

\section{References}

1. Arriagada R, Le MG, Rochard F, Contesso G. Conservative treatment versus mastectomy in early breast cancer: patterns of failure with 15 years of follow-up data. Institut GustaveRoussy Breast Cancer Group. J Clin Oncol. 1996;14:1558-64.

2. van Dongen JA, Voogd AC, Fentiman IS, Legrand C, Sylvester $\mathrm{RJ}$, Tong D, et al. Long-term results of a randomized trial comparing breast-conserving therapy with mastectomy: European Organization for Research and Treatment of Cancer 10801 trial. J Natl Cancer Inst. 2000;92:1143-50.

3. Veronesi U, Cascinelli N, Mariani L, Greco M, Saccozzi R, Luini A, et al. Twenty-year follow-up of a randomized study comparing breast-conserving surgery with radical mastectomy for early breast cancer. N Engl J Med. 2002;347:1227-32.

4. Fisher B, Anderson S, Bryant J, Margolese RG, Deutsch M, Fisher ER, et al. Twenty-year follow-up of a randomized trial comparing total mastectomy, lumpectomy, and lumpectomy plus irradiation for the treatment of invasive breast cancer. $\mathrm{N}$ Engl J Med. 2002;347:1233-41.

5. Poggi MM, Danforth DN, Sciuto LC, Smith SL, Steinberg SM,
Liewehr DJ, et al. Eighteen-year results in the treatment of early breast carcinoma with mastectomy versus breast conservation therapy: the National Cancer Institute Randomized Trial. Cancer. 2003;98:697-702.

6. Blichert-Toft M, Rose C, Andersen JA, Overgaard M, Axelsson $\mathrm{CK}$, Andersen KW, et al. Danish randomized trial comparing breast conservation therapy with mastectomy: six years of lifetable analysis. Danish Breast Cancer Cooperative Group. J Natl Cancer Inst Monogr. 1992;(11):19-25.

7. Agarwal S, Pappas L, Neumayer L, Kokeny K, Agarwal J. Effect of breast conservation therapy vs mastectomy on disease-specific survival for early-stage breast cancer. JAMA Surg. 2014;149:267-74.

8. Chen K, Liu J, Zhu L, Su F, Song E, Jacobs LK. Comparative effectiveness study of breast-conserving surgery and mastectomy in the general population: A NCDB analysis. Oncotarget. 2015;6:40127-40.

9. Pyfer B, Chatterjee A, Chen L, Nigriny J, Czerniecki B, Tchou $\mathrm{J}$, et al. Early postoperative outcomes in breast conservation 
surgery versus simple mastectomy with implant reconstruction: a NSQIP analysis of 11,645 patients. Ann Surg Oncol. 2016;23:92-8.

10. Onitilo AA, Engel JM, Stankowski RV, Doi SA. Survival comparisons for breast conserving surgery and mastectomy revisited: community experience and the role of radiation therapy. Clin Med Res. 2015;13:65-73.

11. van Maaren MC, de Munck L, de Bock GH, Jobsen JJ, van Dalen T, Linn SC, et al. 10 year survival after breast-conserving surgery plus radiotherapy compared with mastectomy in early breast cancer in the Netherlands: a population-based study. Lancet Oncol. 2016;17:1158-70.

12. Ragaz J, Olivotto IA, Spinelli JJ, Phillips N, Jackson SM, Wilson $\mathrm{KS}$, et al. Locoregional radiation therapy in patients with highrisk breast cancer receiving adjuvant chemotherapy: 20-year results of the British Columbia randomized trial. J Natl Cancer Inst. 2005;97:116-26.

13. Overgaard M, Nielsen HM, Overgaard J. Is the benefit of postmastectomy irradiation limited to patients with four or more positive nodes, as recommended in international consensus reports? A subgroup analysis of the DBCG 82 b\&c randomized trials. Radiother Oncol. 2007;82:247-53.

14. EBCTCG (Early Breast Cancer Trialists' Collaborative Group), McGale P, Taylor C, Correa C, Cutter D, Duane F, et al. Effect of radiotherapy after mastectomy and axillary surgery on 10 year recurrence and 20-year breast cancer mortality: metaanalysis of individual patient data for 8135 women in 22 randomised trials. Lancet. 2014;383:2127-35.

15. National Comprehensive Cancer Network. NCCN clinical practice guidelines in oncology: breast cancer, version 2 . Fort Washington, PA: National Comprehensive Cancer Network; 2017.

16. Mackey JR, Martin M, Pienkowski T, Rolski J, Guastalla JP, Sami A, et al. Adjuvant docetaxel, doxorubicin, and cyclophosphamide in node-positive breast cancer: 10-year follow-up of the phase 3 randomised BCIRG 001 trial. Lancet Oncol. 2013;14:72-80.

17. Early Breast Cancer Trialists' Collaborative Group (EBCTCG). Effects of chemotherapy and hormonal therapy for early breast cancer on recurrence and 15-year survival: an overview of the randomised trials. Lancet. 2005;365:1687-717.

18. Early Breast Cancer Trialists' Collaborative Group (EBCTCG), Peto R, Davies C, Godwin J, Gray R, Pan HC, et al. Comparisons between different polychemotherapy regimens for early breast cancer: meta-analyses of long-term outcome among 100,000 women in 123 randomised trials. Lancet. 2012;379:43244.

19. Verrill M. Chemotherapy for early-stage breast cancer: a brief history. Br J Cancer. 2009;101 Suppl 1:S2-5.

20. Kim YJ, Park W, Ha B, Park B, Joo J, Kim TH, et al. Postmastectomy radiotherapy in patients with pT1-2N1 breast cancer treated with taxane-based chemotherapy: a retrospective multicenter analysis (KROG 1418). Cancer Res Treat. 2017;49: 927-36.

21. Kim J, Kim JH, Kim OB, Oh YK, Park SG. Clinical significance of the lymph node ratio in N1 breast cancer. Radiat Oncol J. 2017;35:227-32.

22. Poortmans P, Aznar M, Bartelink H. Quality indicators for breast cancer: revisiting historical evidence in the context of technology changes. Semin Radiat Oncol. 2012;22:29-39.

23. Hershman DL, Wright JD. Comparative effectiveness research in oncology methodology: observational data. J Clin Oncol. 2012;30:4215-22.

24. Lai SF, Chen YH, Kuo WH, Lien HC, Wang MY, Lu YS, et al. Locoregional recurrence risk for postmastectomy breast cancer patients with T1-2 and one to three positive lymph nodes receiving modern systemic treatment without radiotherapy. Ann Surg Oncol. 2016;23:3860-9.

25. Miyashita M, Tada H, Suzuki A, Watanabe G, Hirakawa H, Amari M, et al. Minimal impact of postmastectomy radiation therapy on locoregional recurrence for breast cancer patients with 1 to 3 positive lymph nodes in the modern treatment era. Surg Oncol. 2017;26:163-70.

26. Yu JI, Park W, Choi DH, Huh SJ, Nam SJ, Kim SW, et al. Prognostic modeling in pathologic N1 breast cancer without elective nodal irradiation after current standard systemic management. Clin Breast Cancer. 2015;15:e197-204.

27. Yu JI, Park W, Huh SJ, Choi DH, Lim YH, Ahn JS, et al. Determining which patients require irradiation of the supraclavicular nodal area after surgery for N1 breast cancer. Int J Radiat Oncol Biol Phys. 2010;78:1135-41.

28. Ahn KJ, Park J, Choi Y. Lymphovascular invasion as a negative prognostic factor for triple-negative breast cancer after surgery. Radiat Oncol J. 2017;35:332-9.

29. Cuzick J. Statistical controversies in clinical research: longterm follow-up of clinical trials in cancer. Ann Oncol. 2015;26: 2363-6. 